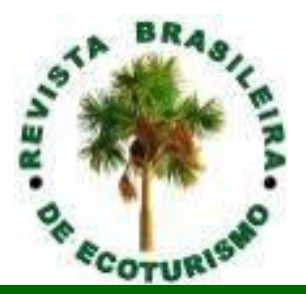

\title{
Relação entre turismo e dinâmica da paisagem em Bonito (MS) na perspectiva do modelo GTP (Geossistema-Território- Paisagem)
}

\section{Relationship between tourism and landscape dynamics in Bonito (MS, Brazil) in view of the GTP model (Geosystem- Territory-Landscape)}

\author{
Waldir Leonel, Mercedes Abid Mercante, José Sabino, \\ Mauro Henrique Soares da Silva, Milton Augusto Pasquotto Mariano
}

\section{RESUMO}

O Município de Bonito, Mato Grosso do Sul, tem desenvolvido a atividade de turismo desde o início dos anos 1990, levando à necessidade de infraestrutura física e turística para atender às demandas do fluxo de turistas, bem como à população local. Essas ações influenciam na mudança da paisagem. O referencial teórico suscitou questionamentos sobre a atividade do turismo praticado no Município. Para abranger as diversas variáveis que interferem no destino turístico, esta investigação utilizará uma proposta metodológica fundamentada nos conceitos de Geossistema-Território-Paisagem (GTP). Com a aplicação deste modelo, os aspectos do geossistema, do território e da paisagem são elementos intrínsecos que envolvem a sociedade em sua ampla discussão, visto a necessidade de se compreender o processo social e ambiental na constituição desses elementos. Busca-se analisar de forma multitemporal a dinâmica da mudança da paisagem e suas influências na evolução do turismo em Bonito, Mato Grosso do Sul, o qual teve um rápido desenvolvimento, no estabelecimento de empreendimentos turísticos, nos últimos 30 anos, apresentando diferentes impactos antrópicos que possam comprometer a sua qualidade ambiental. Assim, buscou-se compreender a dinâmica de evolução, no meio rural e urbano do Município, por meio da identificação de aspectos relacionados às mudanças da paisagem. Foram analisados dados elaborados inicialmente em gabinete, na confecção de mapasbase, utilizando o SPRING 5.2.6 (Sistema de Processamento de Informações Georreferenciadas). Após esta etapa, foi realizado o trabalho de campo, com registros de notas e de fotografias. Os dados levantados foram agrupados e sistematizados por categorias que contêm informações que atendam aos objetivos do Modelo GTP. Dessa forma, os resultados contribuem para avaliar a trajetória do cenário local e realizar reflexões sobre as influências sofridas pela atividade econômica ali estudada, notadamente o turismo. Verificou-se nas imagens grande alteração no uso do solo, havendo decréscimo de vegetação em geral, corpo hídrico e solo exposto, aumento da vegetação de pastagens, área urbana, de atrativos turísticos e de lavouras temporárias. Os resultados demonstraram diferenças entre os anos de 1984 e 2014 na mudança da paisagem. As análises multitemporais contribuíram na compreensão da necessidade do planejamento em relação ao uso e ocupação de determinadas áreas, minimizando impactos decorrentes das ações antrópicas.

PALAVRAS-CHAVE: Sociedade; Ambiente; GTP, Turismo. 


\section{ABSTRACT}

The city of Bonito, Mato Grosso do Sul, has developed the tourism activity since the early 1990s, influencing the need for physical infrastructure and tourism to meet the demands of the flow of tourists and the local population. These actions influence the changing landscape. The theoretical framework has raised questions about the tourism activity practiced in the city. To cover the different variables that affect the tourist destination, this research uses a methodology based on the concepts of Geosystem-Territory-Landscape (GTP). With the application of this model, aspects of geosystem, territory and landscape are intrinsic elements involving society in their broad discussion, as the need to understand the social and environmental process in the formation of these elements. Seeks to analyze multi-temporal shape the landscape changing dynamics and their influence on the evolution of tourism in Bonito, Mato Grosso do Sul, which had a rapid development in the establishment of tourism enterprises in the last 30 years, with different human impacts, that might compromise their environmental quality. Like this, we sought to understand the dynamics of development in rural and urban areas of the municipality, through the identification of aspects related to landscape changes. Data were analyzed initially developed in office, in the preparation of base maps using the 5.2.6 SPRING (Georeferenced Information Processing System). After this step was carried out fieldwork, with records of notes and photographs. The collected data were grouped and systematized by category containing information that meets the objectives of the GTP Model. In this way, the results contribute to evaluate the trajectory of the local scene and conduct reflections on the influences suffered by economic activity there studied, notably: tourism. It was the major change images in land use, with decrease of vegetation in general, water body and exposed soil, increasing vegetation pastures, urban, tourist attractions and temporary crops. The results showed differences between the years 1984 and 2014 in changing the landscape. The multi-temporal analysis contributed to the understanding of the need for planning in relation to the use and occupation of certain areas, minimizing impacts of anthropic actions.

KEYWORDS: Society; Environment; GTP, Tourism.

\section{Introdução}

O Município de Bonito está localizado na região sobre o planalto da Bodoquena. Possui extensas áreas carbonáticas, as quais se tornaram importantes, do ponto de vista das geociências, e por sua beleza natural e diversidade que se tornaram atrativos para o segmento de turismo. Atualmente, ocupa a posição de um dos destinos brasileiros mais procurados para a prática de ecoturismo e turismo de aventura, conforme ações de publicidade sobre o atrativo. Ainda, é conhecido por possuir uma rica fauna e flora, cavernas com características de relevo cárstico específico, além de rios com águas cristalinas, devido às características do solo calcário da região.

Devido sua riqueza e potencial natural, o Município tem no uso dos recursos naturais, quando consolidados como atrativos turísticos, 0 desenvolvimento do turismo, que se tornou uma atividade que somou às principais práticas econômicas da região há alguns anos (CERDOURA, 
2013), e que a cada ano busca qualidade para os produtos turísticos oferecidos na região.

Conforme Barbosa e Zamboni (2000), a economia do Município até a década de 1980 era baseada na agricultura e pecuária e, com o passar do tempo, o turismo foi tomando espaço na região. Em meados de 1986, alguns proprietários rurais notaram a possibilidade de abrir suas propriedades para visitação. De acordo com Banducci e Moretti (2001), foi na década de 1990 que o turismo foi de fato implantado na região de Bonito, sendo inserido como uma atividade promissora aliada ao desenvolvimento regional.

Cabe destacar os trabalhos de relevância sobre o Município, em que diferentes objetivos, critérios e metodologias relacionadas ao turismo e o meio ambiente foram aplicados, como o de Vargas (1998) que teve como objetivo a análise do desenvolvimento da educação ambiental no Município; Mariani (2000) analisou a questão dos atrativos ligados à água; Trentin (2005) realizou uma análise das políticas públicas desenvolvidas em Bonito a partir do início do turismo; a sustentabilidade, os dilemas e as perspectivas para o Município foram tema da tese de Lunas (2006). Por sua vez, Dechandt (2007) realizou um estudo comparativo do ecoturismo e seu desenvolvimento entre os Municípios da Chapada Diamantina (BA) e Bonito (MS); e, por fim, Oliveira (2010) teve por objetivo avaliar alguns aspectos da gestão ambiental, analisando a implantação e o desenvolvimento. Cabe destacar que neste último estudo, mesmo sendo apresentado em 2010, o período de levantamento de campo ocorreu entre os anos de 1989 a 2004.

Assim, surge a preocupação em estudar o desenvolvimento desta atividade no Município, a qual possivelmente promoveu transformações pelas ações na paisagem nessas últimas décadas, afetando diferentes aspectos, dentre eles os recursos naturais, a organização social e a cultural no local.

O desenvolvimento desta investigação busca responder a seguinte questão norteadora: Qual o impacto do turismo na paisagem natural do Município de Bonito na perspectiva metodológica do modelo GTP (Geossistema-território-paisagem) para a análise ambiental?

Este artigo buscou compreender a dinâmica de evolução do turismo, no meio rural e urbano do Município de Bonito, a partir da década de 1980, por meio da identificação de aspectos relacionados às mudanças da paisagem. Especificamente pretendeu-se elaborar mapas de épocas distintas, sendo uma em 2014 e outras pretéritas (1984, 1994 e 2004) para, assim, realizar uma análise comparativa da mudança da paisagem no decorrer deste período.

\section{Bonito no contexto geográfico}

O Município Bonito, Mato Grosso do Sul, está localizado na região sobre 0 planalto da Bodoquena, atualmente conhecido nacional e internacionalmente por sua beleza natural e por sua diversidade de atrativos. Ocupa a posição de um dos destinos mais procurados para a prática de 
ecoturismo e turismo de aventura, conforme ações de publicidade sobre o local (BARBOSA; ZAMBONI, 2000). Ainda, são encontradas formações do relevo cárstico regional com cavernas, sumidouros, dolinas, rios com águas cristalinas (BOGGIANI, 1999).

Situa-se na Serra da Bodoquena, sudoeste de Mato Grosso do Sul, distante $297 \mathrm{~km}$ da capital, Campo Grande; faz parte da microrregião Geográfica da Bodoquena (MRH 09), e a sede está localizada nas coordenadas $21^{\circ} 07^{\prime} 16^{\prime \prime S}$ e $56^{\circ} 28^{\prime} 55^{\prime \prime O}$ (Figura 1). Possui área total de $4.934 \mathrm{~km}^{2}$, correspondendo a $1,40 \%$ das terras do Estado. Possui os Municípios limítrofes de Miranda, Bodoquena e Anastácio ao norte; Porto Murtinho, Jardim e Guia Lopes da Laguna ao sul; a leste o Município de Nioaque e, a Oeste, Porto Murtinho e Bodoquena (DIAS, 1998). Os principais rios do Planalto da Bodoquena são o Formoso, o Perdido, o Salobra e o Rio da Prata (SCREMIN-DIAS et al., 1999) e o clima na região é subquente-úmido (IBGE, 2000).

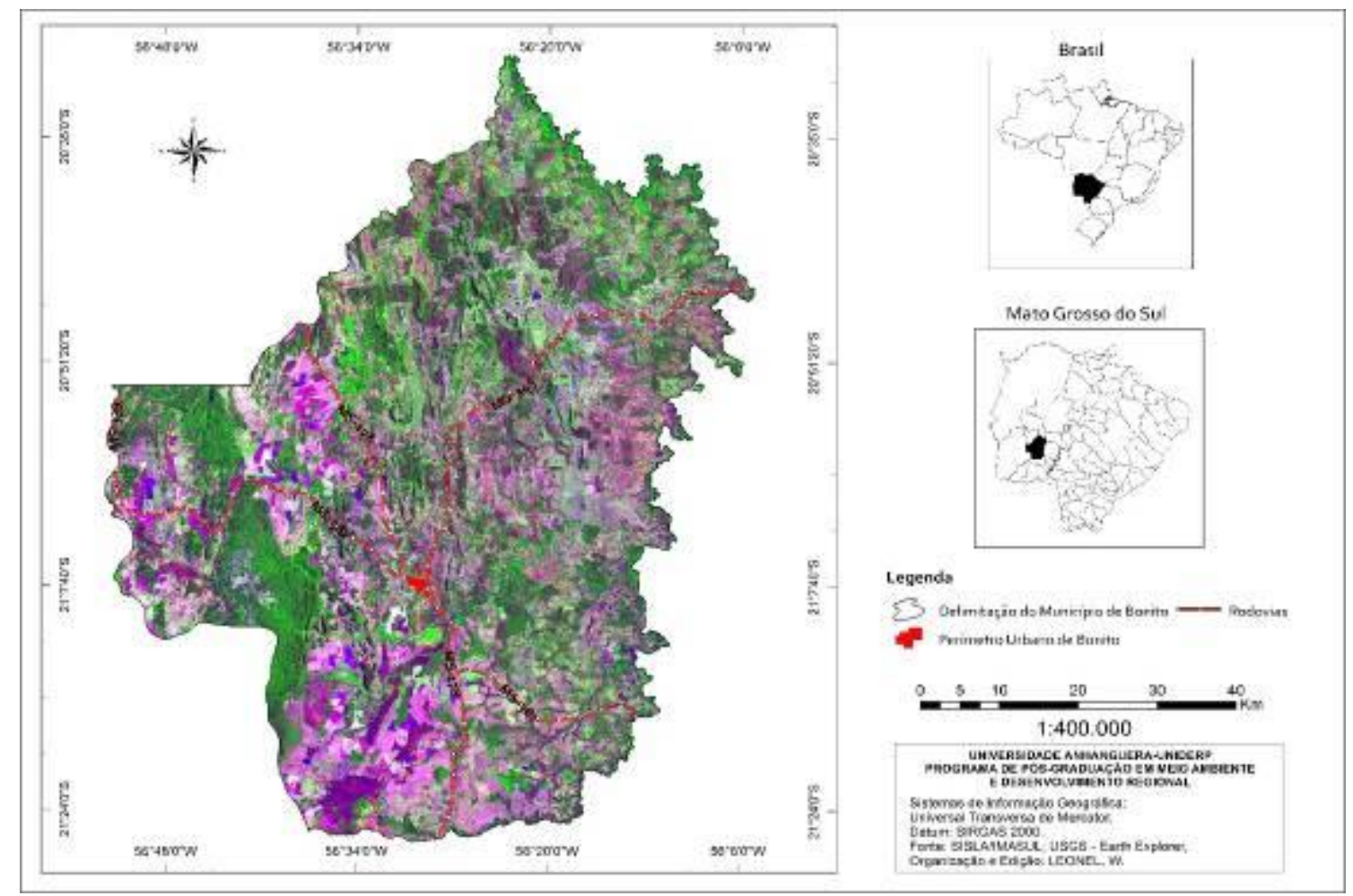

Figura 1: Localização do Município de Bonito, Mato Grosso do Sul. Figure 1: Location of Bonito, Mato Grosso do Sul.

A cidade de Bonito tem 19.587 habitantes, residindo na sede 18.363 e, no Distrito Águas de Miranda, 1.224. Destes, residem na área urbana 16.159 e, na área rural, 3.428. No "ranking" estadual de 2010, ocupa o $66^{\circ}$ lugar no Índice de Desenvolvimento Humano Municipal (IDH-M), com valor de 0,670 (IBGE, 2010).

O clima é tropical com inverno seco e verão úmido; no inverno a temperatura varia entre 15 a $20^{\circ} \mathrm{C}$ e, no verão, podendo chegar aos $38^{\circ} \mathrm{C}$. A 
precipitação pluviométrica anual varia em torno de 1.500 milímetros e tem um período seco de três a quatro meses por ano (CPTEC-INPE, 2014).

A vegetação do Planalto da Bodoquena diversifica conforme o tipo de solo, sendo encontradas vegetações típicas de Cerrado, Cerradão, Campo Cerrado e Campo Limpo. Há, também, a ocorrência de floresta estacional semidecidual e floresta estacional decidual submontana. Porém, a vegetação predominante é do Cerrado, destacando a floresta Tropical Estacional Decidual associada às rochas calcárias e matas ciliares ou ribeirinhas, associadas sempre a solos férteis às margens dos rios (SCREMIN-DIAS, 1999).

Segundo Vargas (2001), o relevo define-se basicamente por meio de duas unidades: o Planalto da Bodoquena e a depressão de Miranda. A Serra da Bodoquena apresenta formas e características relacionadas às litologias calcárias, comportando altimetrias que variam de quatrocentos a seiscentos metros, enquanto a depressão de Miranda apresenta superfície mais baixa, variando de 100 a 300 metros de altitude. A sede do Município encontra-se a 315 metros de altitude.

De acordo com Dias (2000, p. 21), Bonito apresenta paisagens com feições cársticas, logo, apresentam características que estarão diretamente relacionadas ao fenômeno cárstico, destacando ainda que:

O fenômeno cárstico de Bonito produziu extensas plataformas de vertentes retilíneas, desprovidas de vales profundos, entremeadas pelos mogotes que se erguem abruptamente, sem uma transição do plano para o inclinado. São paisagens decorrentes da predominância da infiltração em detrimento do escoamento superficial, o que faz com que o processo de dissolução suplante a erosão. Excetua-se o grande vale em forma de canyon do Rio Perdido, que drena o maciço da Bodoquena.

Boggiani et al. (1999) descrevem Bonito, analisando suas águas e suas formações calcárias:

... às águas serem ricas em carbonatos de cálcio dissolvido e pela atividade de algas e musgos que dão origem a barreiras de calcário que crescem verticalmente ao longo dos anos [...] A região é caracterizada por apresentar exposições de calcários, sendo que a presença deste tipo de rocha resultou na origem desta paisagem atípica [...] Bonito apresenta cavernas com lagos e rios subterrâneos. Isto ocorre porque o calcário, constituído basicamente de carbonato de cálcio, é uma rocha solúvel, ou seja, no contato com águas aciduladas o carbonato de cálcio se dissolve e é levado pelas águas. 
Segundo Mariani (2000), até a década de 1970, os recursos hídricos da região serviam quase que exclusivamente ao lazer dos habitantes, sendo visitados principalmente pelos amantes da pesca, inclusive pesca de arpão, com a aquiescência dos proprietários rurais da região. Ainda, afirma que os pontos visitados eram a Gruta do Lago Azul e a llha do Padre, que recebeu infraestrutura para lazer, ficou conhecida por Balneário llha do Padre e, posteriormente, passou a integrar o conjunto de atrativos turísticos de Bonito.

\section{Geossistema, Território e Paisagem}

Em seu artigo, "Paisagem e Geografia física global: um esboço metodológico", Bertrand (2004) apresentou sua proposta integradora dos sistemas formados pelas interações dos sistemas bióticos, abióticos e antrópicos, com a finalidade de compreender os fenômenos entre sociedade-natureza.

Bertrand (2004, p.141) também defende que é o valor da visão holística da paisagem (síntese) que contrapõe à análise compartimentada, que é comumente encontrada na Geografia:

... o resultado da combinação dinâmica, portanto instável, de elementos físicos, biológicos e antrópicos que, reagindo dialeticamente uns sobre os outros, fazem da paisagem um conjunto único e indissociável, em perpétua evolução.

Silva (2012, p. 58) afirma que é necessário o estudo interdisciplinar, e que não adianta uma discussão por especialistas de diferentes áreas sobre o mesmo local se não houver um diálogo entre os procedimentos e os resultados.

... essas afirmações encaminham os estudos de paisagem para uma visão de integração entre os elementos físicos e humanos que a compõe, entendendo que toda paisagem faz parte de um território e é regida por tal conceito, sendo, portanto, necessário para as pesquisas de paisagem realizar uma abordagem contendo três entradas: uma naturalista (o geossistema), uma socioeconômica (Território) e uma sociocultural (a paisagem).

Dessa forma, entende-se paisagem conforme descrito anteriormente e argumenta-se que para o estudo dessa paisagem faz-se necessário analisar alguns pontos importantes. Deve-se ater à delimitação que é definida por BERTRAND (2004), que ressalta ser impossível encontrar na natureza um sistema que tenha limites próprios para cada ordem de fenômeno. Outros elementos são as relações, que devem considerar as combinações e as relações entre os elementos e os fenômenos que se convergem. E, por fim, a escala, pois a paisagem deve ser situada no tempo 
e espaço, considerando que existe o início e o término de cada ordem de fenômenos.

Conforme Souza (2010), abordar o ambiente por meio de um aporte teórico-metodológico que pretenda lidar com a complexidade dos fenômenos entre natureza e sociedade, e inclinar à proposta "bertrandiana" para a compreensão dos fenômenos geográficos e entrada na questão socioambiental, torna-se um desafio inovador, no caso, o turismo.

Nesse sentido, o estudo do ambiente, de forma sistêmica, é sustentado por teorias de Bertrand e Bertrand (2007), Sotchava (1977); Monteiro (2001).

Define-se o conceito de sistema:

... como um conjunto de fenômenos que se desenvolvem a partir dos fluxos de matéria e energia, que tem origem a partir de uma interdependência, no qual surge uma nova entidade global, integral e dinâmica, permitindo assim uma atitude dialética, a necessidade de análise e de visão do todo, a fim de se atuar sobre o meio ambiente. (TRICART, 1977, p. 42)

Após Bertrand analisar o conceito de geossistema criado por Sotchava (1977), incorpora a ele a dimensão da ação antrópica, elemento de estudo e interface no turismo, criando, assim, uma categoria espacial de componentes relativamente homogêneos, cuja dinâmica resulta da interação entre o potencial ecológico, a exploração biológica e a ação antrópica.

A partir desse elemento de análise e dessa interação ecológica, biológica e ação antrópica, busca-se novamente na geografia o método que possa amparar os estudos do ambiente no turismo e suas contribuições para análise de localidades.

Esse método, criado em 1997, por Bertrand, é chamado por diferentes autores de GTP (Geossistema-Território-Paisagem), podendo ser compreendido pelas três vias interdependentes que trabalham cientificamente na construção do espaço geográfico. Tem como interesse epistemológico e metodológico a preocupação de preservar a complexidade e a diversidade do ambiente, na tentativa de auxiliar na superação da ruptura entre sociedade e natureza.

Segundo Rosolém e Archela (2010, p. 07), podem-se entender os elementos da seguinte forma:

O geossistema constituído pelos elementos geográficos e sistêmicos no qual são compostos por elementos abióticos, bióticos e antrópicos, em que abrange também os conceitos espacial, natural e antrópico. O território é a entrada em que permite analisar as ações e o funcionamento da questão social e econômica no espaço, considerando o tempo para relatar o recurso, a gestão, a redistribuição, a poluição e a 
despoluição. A paisagem que abrange não somente 0 visível, mas também a construção cultural e econômica de um espaço geográfico. Nela contém o território, sua organização espacial e seu funcionamento, e se reproduz nos elementos do geossistema.

Para Rougerie e Beroutchachvili (1991), o geossistema é também considerado como um sistema natural, complexo e integrado, no qual há circulação de energia e matéria, e ocorre exploração biológica, incluindo aquela praticada pelo homem. É composto basicamente por três fatores, os abióticos (litosfera, atmosfera, hidrosfera que formam o geoma), os bióticos (flora e fauna) e os antrópicos (formado pelo homem e suas atividades).

Acredita-se aqui que o Modelo GTP seja uma perspectiva metodológica que contemple os elementos necessários para a correlação dos aspectos físicos, políticos e socioculturais que envolvem as questões que norteiam a pesquisa, sendo eficaz para a análise do desenvolvimento do turismo em uma localidade. Bertrand, portanto, amplia a conjuntura metodológica para a compreensão do meio ambiente. Tal conjuntura é baseada na tríade denominada pelo autor de GTP, que pode ser compreendida pelas três vias interdependentes que trabalham cientificamente na construção do espaço geográfico, tendo como interesse epistemológico e metodológico a preocupação de preservar a complexidade e a diversidade do ambiente, na tentativa de auxiliar na superação da ruptura entre sociedade e natureza (Figura 2).

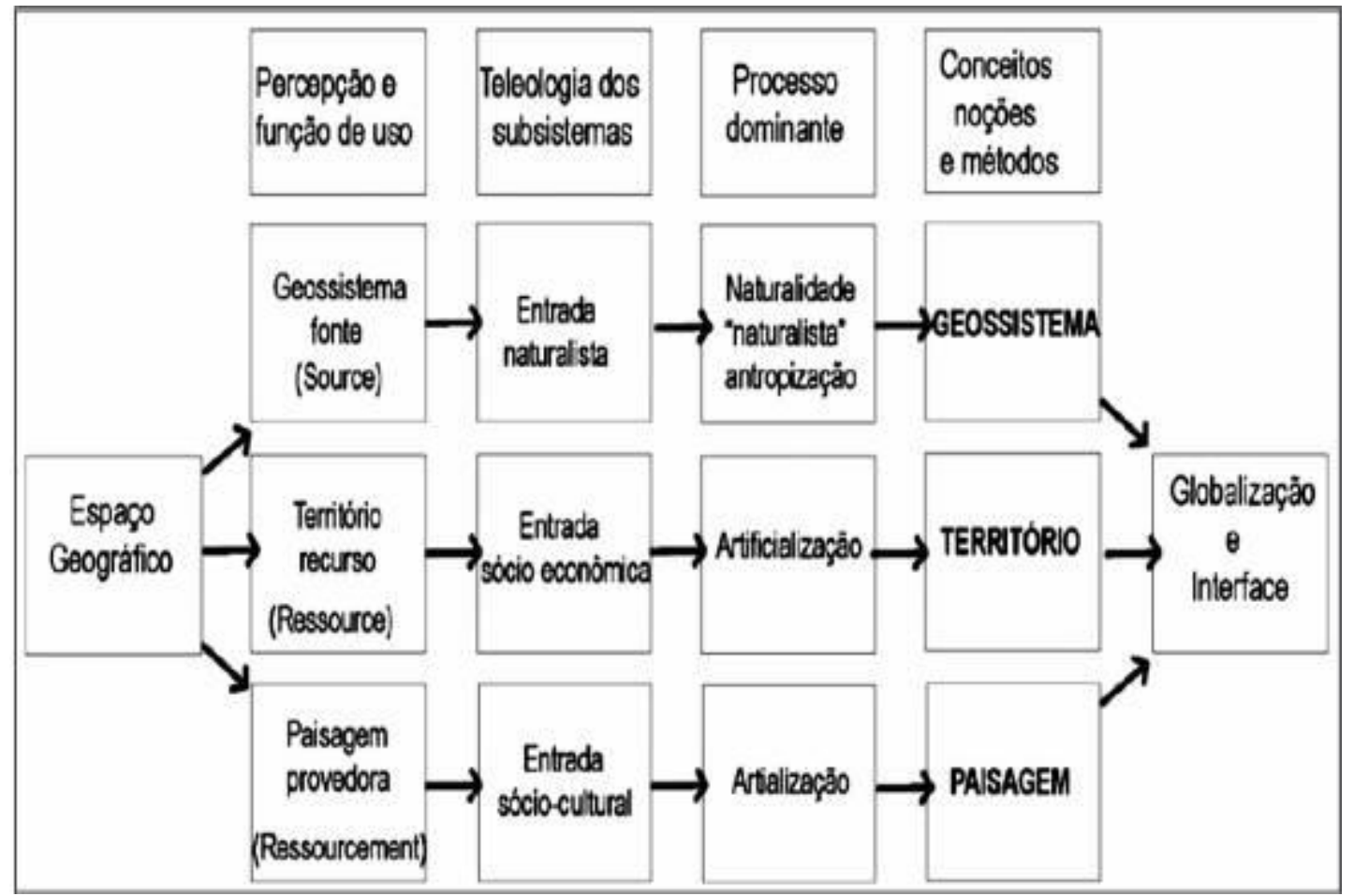

Figura 2: Esquema do Sistema GTP. Adaptado de Bertrand e Bertrand (2007) por Pissinati e Archela (2009)

Figure 2: Scheme of the System GTP. Adapted from Bertrand and Bertrand (2007) by Pissinati e Archela (2009) 
Para uma análise sistêmica, foi necessário considerar diferentes variáveis (biofísicas, políticas, econômicas, socioculturais) da paisagem, que influenciaram na trajetória do processo de implantação do turismo na localidade; optou-se pelo sistema GTP por entender que esse modelo possibilita estabelecer um exercício de correlação entre as variáveis, na busca por uma abordagem integradora.

A utilização dessa metodologia traz diferentes olhares no estudo do turismo, pois, segundo Pissinati e Archela (2009), a meta do GTP é a reaproximação das três dimensões para se analisar o funcionamento de um determinado local de forma holística, buscando atingir as interações dos elementos que mais bem visualizem e compreendam a dinâmica da área estudada.

Ainda, segundo Rosolém e Archela (2010), essa metodologia serve não só para a delimitação e representação cartográfica das áreas, mas também para detectar os problemas existentes e o grau de responsabilidade da ação antrópica sobre os mesmos, para planejar estratégias a fim de conter, reverter ou amenizar os impactos existentes. Pode ser utilizada para revelar as formas de criação, de reprodução e de transformação das estruturas.

Para o estudo no ecoturismo, acredita-se que essa seja uma importante proposta metodológica para a realização de análise e dinâmica da paisagem, que pode ser aplicada a diferentes objetos de estudo que tenham como objetivo a descrição e a análise do espaço geográfico.

A Figura 3 (próxima página) apresenta o modelo GTP de Georges Bertrand com interface voltada para o turismo e o desenvolvimento, representando, assim, a aplicabilidade dos seus conceitos também nas atividades turísticas. Reafirma o que foi dito por Pissinati e Archela (2009), que destacavam a importância de se avaliar as condições em que se encontram os solos, os recursos hídricos e as matas nativas e associá-los com as necessidades sociais e econômicas do local, durante as operações de planejamento e gestão de uma atividade, de uma forma com que sejam coerentes às três dimensões: ambiental, social e econômica.

Entender a complexidade dos sistemas ambientais é um desafio, principalmente quando a metodologia é inserida em outras áreas, que a aplicam buscando significados e respostas em suas ciências. Dessa forma, a utilização do Método GTP orientou a construção e o embasamento teórico desta pesquisa, buscando contribuição para o estudo do turismo. 


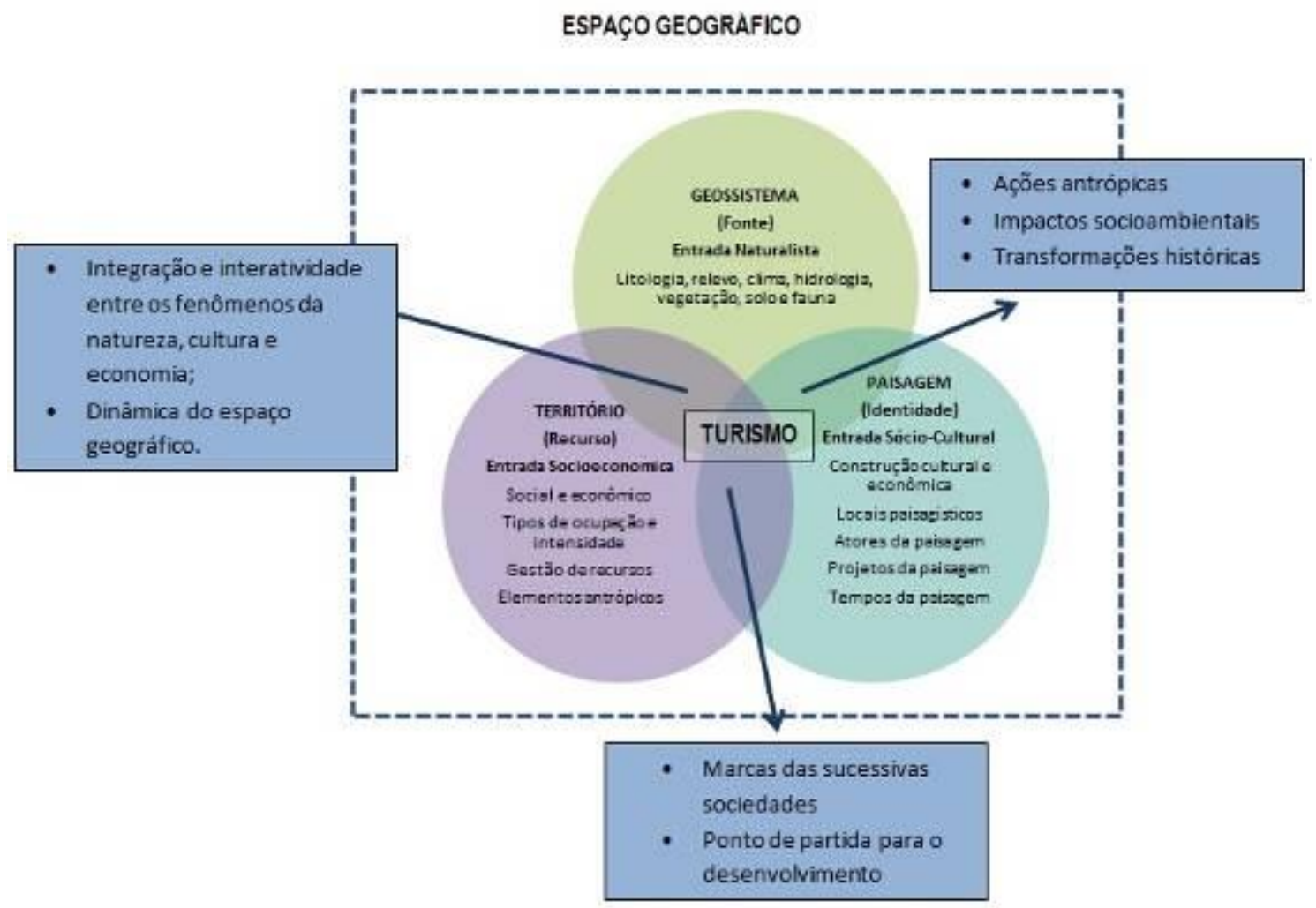

Figura 3: Modelo GTP com interface para o Turismo. Adaptado de BERTRAND e BERTRAND (2007) e organizado por LEONEL, W. (2016).

Figure 3: Model GTP interface for Tourism. Adapted from BERTRAND and BERTRAND (2007) and organized by LEONEL, W. (2016).

\section{Procedimentos Metodológicos}

Para a análise do uso e ocupação do solo de Bonito, a primeira etapa consistiu na aquisição das imagens de satélites do referido Município, adquiridas no catálogo de imagens do Instituto Nacional de Pesquisas Espaciais (INPE) e que se encontram disponíveis para download no formato TIFF, aos usuários cadastrados. As imagens orbitais são do satélite/sensor LandSat 5/TM, referentes à órbita e ponto 226/74 e 226/75, passagem de 18/set/1984, 10/jun/1994 e 05/jun/2004, intervalo de tempo considerado suficiente para identificar as mudanças na paisagem. Para o ano de 2014, utilizaram-se imagens do satélite LandSat 8/OLI, disponível no site da United States Geological Survey (USGS), órbita e 226/74 e 226/75 de 21/set/2014 (Quadro 1).

$\mathrm{Na}$ obtenção das imagens, buscou-se um padrão, ocorrendo a escolha entre os meses do ano em que fosse observado o intervalo máximo de três meses entre estas datas, para haver menos interferência de estações secas e chuvosas. Não foi possível imagens mais próximas das datas, pela ocorrência de nuvens na área de estudo. 
Quadro 1: Satélite, Data da Imagem, Órbita Ponto e Bandas utilizadas em cada imagem no Mapeamento.

Chart 1: Satellite, Image data, Orbit Point and Bands used in each image in the Mapping.

\begin{tabular}{lccc}
\hline Satélite/Sensor & Data da Imagem & Órbita; Ponto. & Bandas Utilizadas \\
\hline Landsat 5/TM & $18 / 09 / 1984$ & $226 ; 74$ e 75. & 3,4 e 5. \\
Landsat 5/TM & $10 / 06 / 1994$ & $226 ; 74$ e 75. & 3,4 e 5. \\
Landsat 5/TM & $05 / 06 / 2004$ & $226 ; 74$ e 75. & 3,4 e 5. \\
Landsat 8/OLI & $21 / 09 / 2014$ & $226 ; 74$ e 75. & 4,5 e 6. \\
\hline
\end{tabular}

\section{Geoprocessamento e Sensoriamento Remoto das Imagens}

Os processos utilizados para o período de 1984 a 2014 foram feitos no software SPRING ${ }^{\circledR}$ versão 5.2.6, um Sistema de Informações Geográficas (SIG) livre, desenvolvido pela Divisão de Processamento de Imagens do INPE e de aquisição gratuita por meios eletrônicos e também do ArcGis $10^{\circledR}$.

As imagens de 2014, foram primeiramente georreferenciadas no Software ArcGis $10^{\circledR}$, baseado numa imagem Geocover corrigida da Nasa S22-20-2000 (GLCF, 2013).

Em seguida, as imagens foram recortadas a partir de um Shapefile do limite do Município. Dispondo das imagens devidamente recortadas, foi realizada então a composição das bandas, utilizando as bandas $3(B), 4(G)$ e $5(\mathrm{R})$, para a melhor diferenciação dos elementos para as três primeiras décadas. Para 2014, utilizou-se das bandas 4(G), 5(R) e 6(B). Anteriormente à composição colorida, aplicou-se contraste Histograma sobre cada banda monocromática. A segmentação foi executada pelo método de crescimento de regiões (SCHOENMAKERS et al., 1991). Optou-se pelo nível de similaridade 08, com área mínima ou limiar para segmentação de 20 pixels. Após a segmentação, efetuou-se o treinamento do sistema, por meio do qual foram obtidas amostras de regiões representativas de acordo com suas áreas de segmentação, para cada uma das classes definidas. Logo depois, foram submetidas à análise da matriz de confusão para ajustes.

Posteriormente, efetuou-se a classificação das imagens, com a utilização do classificador de Histograma com limiar de aceitação de $99 \%$. Para a definição das sete classes: Áreas de lavouras temporárias (agricultura), vegetação de pastagens, solo exposto (área com superfície do solo nu, com mineração ou áreas desmatadas), área de várzea (áreas alagadas ou úmidas), área urbana (construções residenciais, comerciais, rodovias), corpos hídricos (rios, córregos, lagoas intermitentes e permanentes, nascentes) e vegetação natural florestal (todo tipo de vegetação rasteira) utilizou-se o Manual técnico de uso da Terra (IBGE, 2006), com pequenas adaptações nas classificações devido à escala utilizada e à área bastante diversificada (Figura 4). 


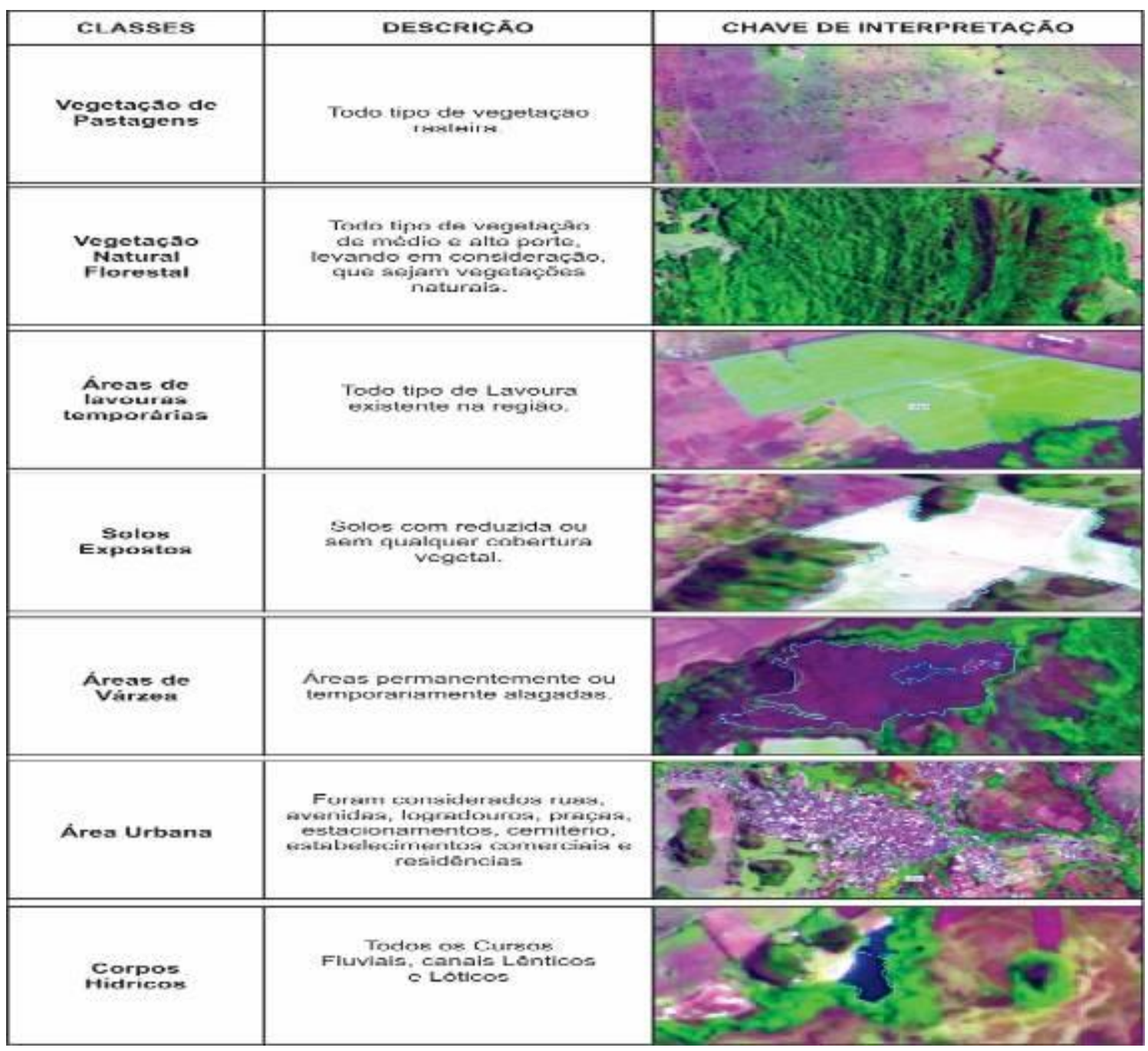

Figura 4: Chave de interpretação de classes utilizadas e suas descrições.

Figure 4: Key interpretation used classes and their descriptions.

Para as Áreas de Atrativos Turísticos (foram analisados os locais em que se encontram os atrativos turísticos), ocorreu uma sobreposição dos pontos.

Com a finalidade de refinar o mapa de uso do solo, procedeu-se a edição matricial e a pós-classificação, permitindo, assim, transformar a imagem classificada em uma imagem de modelo temático. Por fim, foram confeccionados mapas temáticos a partir das imagens classificadas, gerando os mapas de uso e ocupação do solo dos anos de 1984 a 2014, utilizando o módulo Scarta 5.2.6.

O trabalho de campo realizado no mês de junho de 2016, período de estação seca, também chamada de verdade terrestre, teve como objetivo a identificação das características espectrais encontradas na imagem com os tipos de cobertura e uso do solo existente na região. Para esta fase da pesquisa foram utilizados como apoio os seguintes materiais: caderno de campo, GPS (Global Positioning System), imagem reproduzida na escala de 1:450.000, contendo interpretação preliminar via Google Earth, máquina 
fotográfica Nikon EH-69P 42X Optical Zoom, informações sobre a área e roteiro de percurso para observações dos alvos a serem identificados segundo os padrões de forma, cor, arranjos e texturas e, ainda, a contratação de guia local para acompanhamento das áreas identificadas e contextualização de informações sobre os aspectos ou modificações ocorridas nos pontos analisados.

Após o trabalho de campo e com base nas informações observadas aliadas aos registros fotográficos, realizou-se o processo de interpretação da imagem de satélite.

Para Florenzano (2011), a relação de interação do homem com a máquina e o conhecimento sobre o objeto (ou tema) de estudo (relevo, vegetação, área urbana, turismo) facilitam o processo de interpretação e aumentam o potencial de leitura de uma imagem sobre a área geográfica, pois é maior o potencial de informação que ele pode extrair da imagem.

\section{Resultados do Trabalho Empírico}

A partir da metodologia selecionada, foi possível realizar mapas temáticos representando a evolução do processo de uso e ocupação do solo de Bonito (MS).

Analisando as imagens de uso e ocupação do solo, assim como a quantificação da evolução das áreas, observa-se grandes mudanças na paisagem da região realizadas pelo processo de ocupação do espaço ao longo das quatro últimas décadas.

Em 1984, os recursos não eram utilizados como atrativos, já em 2004 e 2014 a maior parte dos atrativos de Bonito já estava em operação, em uma porcentagem de crescimento de área de quase $100 \%$ entre as duas décadas, indo de 3,32 km² em 2004, para 5,78 km² em 2014.

Concomitante, observa-se um acréscimo da área urbana, que em 1984 apresentava $2,50 \mathrm{~km}^{2}$ e em 2014, 6,36 km², um aumento de $39,30 \%$. Alguns loteamentos foram implantados após 2004, como o Loteamento Tarumã e o Loteamento Portal do Rio Formoso (Foto 1) e, também, o Loteamento Solar dos Lagos, que foi uma obra embargada por mais de oito anos, devido a fragilidade da área, local conhecido como "Calcarinho" (Foto 2).
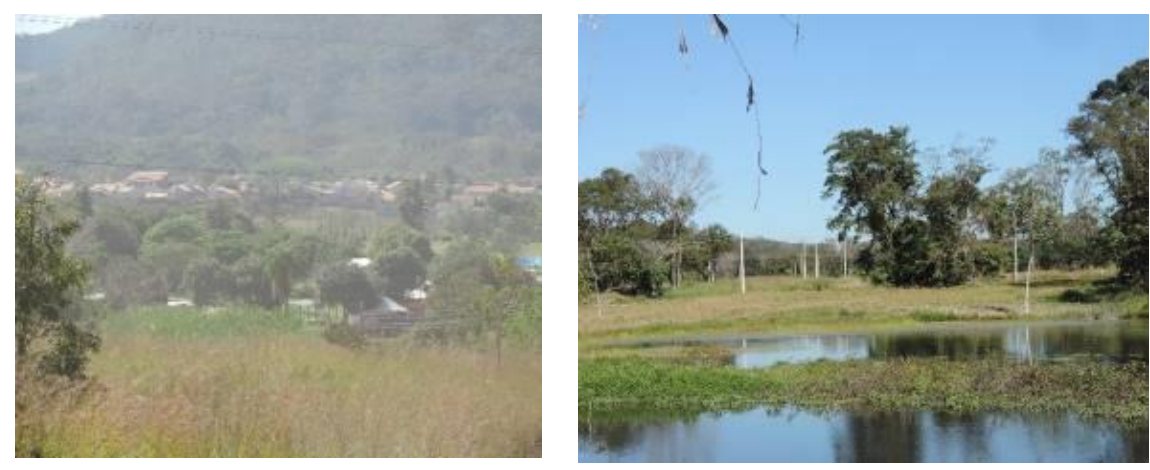

Figura 5: Loteamento Tarumã e Loteamento Solar dos Lagos.

Figure 5: Allotment Tarumã and Allotment Solar Lakes. 
Já as classes que destacam o valor de conservação ambiental demonstraram resultados referentes à perda de vegetação natural florestal, que mostram uma redução de aproximadamente $800 \mathrm{~km}^{2}$, entre as décadas de 1984 e 2014, bem como referentes aos corpos hídricos, uma redução de quase $8 \mathrm{~km}^{2}$. E, ainda, o aumento de área de solo exposto em 2014, em uma área aproximada de 4,21 km².

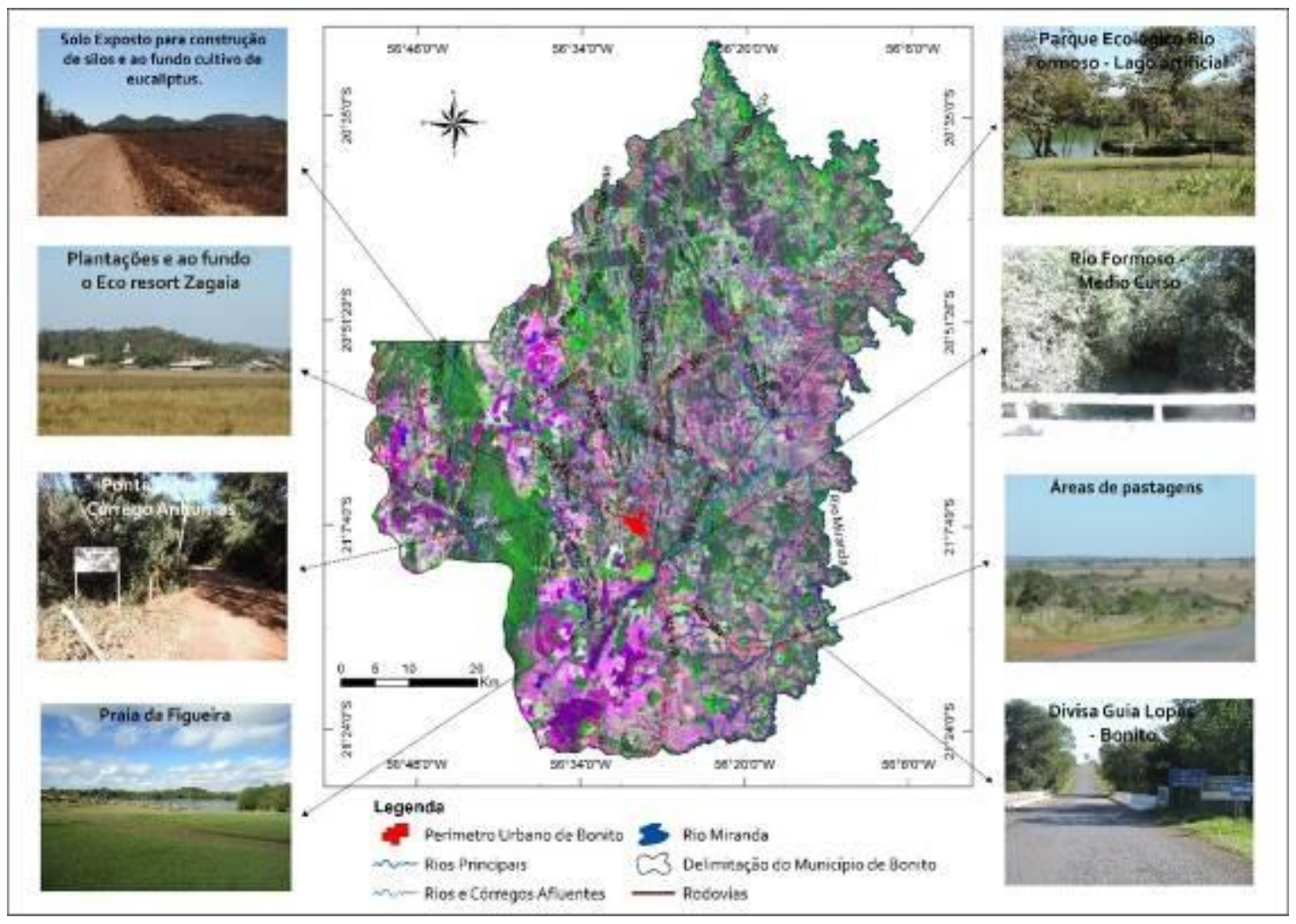

Figura 6: Chaves de interpretação: 1) Solo exposto, e ao fundo plantação de Eucaliptus (Eucalyptus sp.); 2) área de lavouras temporárias - milho (Zea mays) e ao fundo empreendimento turístico; 3) Corpo hídricos - Córrego Anhumas; 4 e 5) Empreendimento turístico; 6) Corpo hídrico - Rio Formoso; 7) Contraste de tonalidade entre tipos de pasto, a beira da estrada observa-se um misto de capim braquiária (Brachiaria decumbens) e capim rabo de burro (Andropogon condensatus); 8) Corpo hídrico - Rio Miranda (Divisa de municípios).

Figure 6.: Interpretation Keys: 1) exposed soil, and background planting Eucalyptus (Eucalyptus sp.); 2) area of temporary crops - corn (Zea mays) and tourist development fund; 3) Water Body - Stream Anhumas; 4 e 5) Tourist Resort; 6) water body - Rio Formoso; 7) Tonal Contrast between types of pasture, the roadside is observed a mixture of Brachiaria grass (Brachiaria decumbens) and grass donkey tail (Andropogon condensatus); 8) water body - Rio Miranda (Motto municipalities).

Na Figura 7, podem ser observados os mapas temáticos referentes ao uso e ocupação do solo das imagens do Município de Bonito, para os anos de 1984, 1994, 2004 e 2014. 


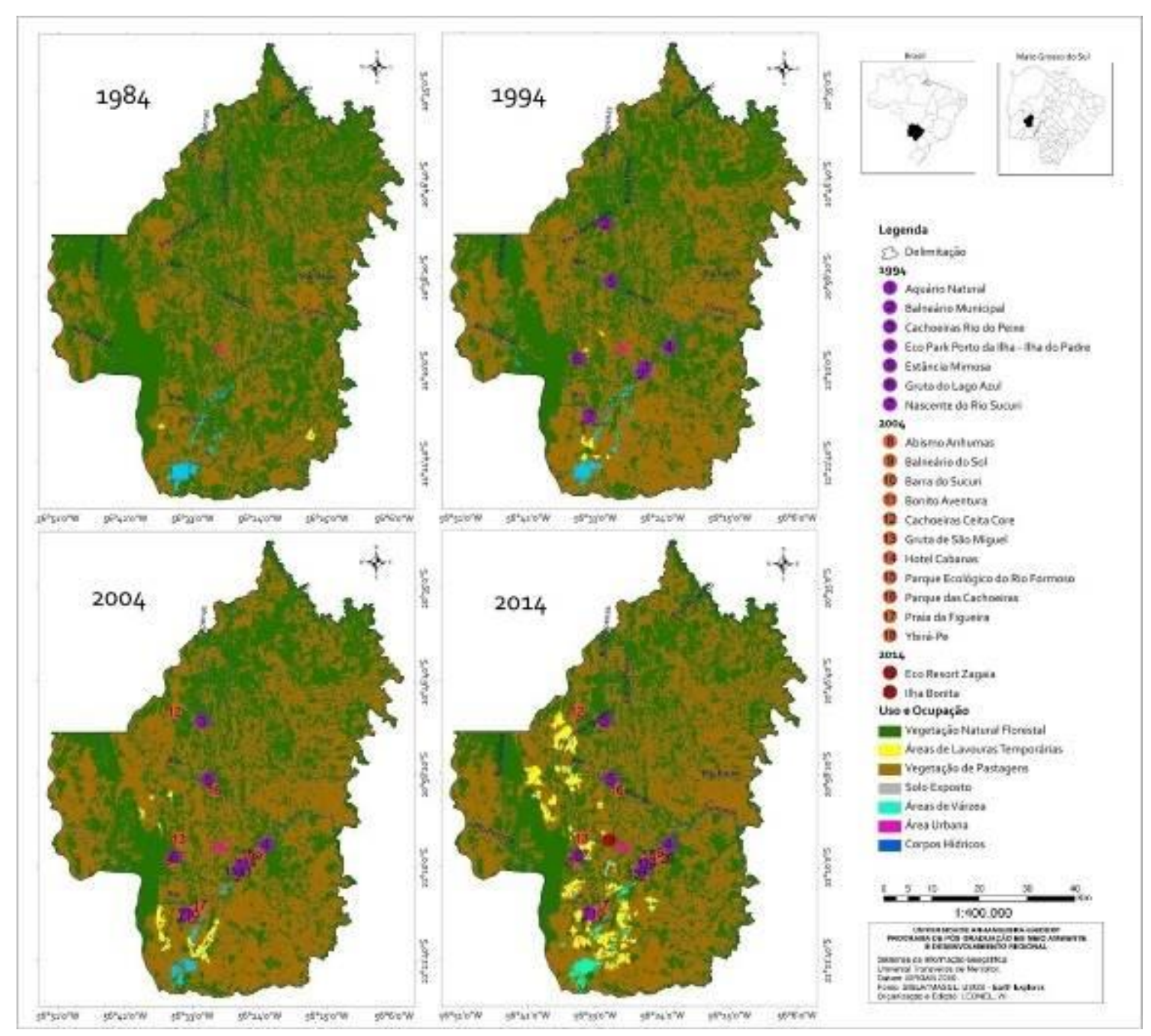

Figura 7: Mapa do uso e ocupação do solo do Município de Bonito, Mato Grosso do Sul.

Figure 7: Map of the use and occupation of Bonito, Mato Grosso do Sul.

Os dados demonstraram um acréscimo substancial de áreas relativas à vegetação de pastagens e lavouras temporárias, esta última um acréscimo de $160 \mathrm{~km}^{2}$ (Tabela 1).

Os dados apresentam um aumento da área urbana considerável: acreditava-se em um crescimento da área urbana, tendo em vista a implantação de novos atrativos turísticos, mas os gráficos não destacam tal expansão. Porém, chama a atenção o acréscimo da vegetação de pastagens em detrimento da vegetação natural do Município, fato preocupante, considerando que a natureza é o produto vendido pelo ecoturismo da região. 
Tabela 1: Evolução do Uso e Ocupação do Solo no Município de Bonito/MS nos anos de 1984, 1994, 2004 e 2014.

Table 1: Use Evolution and Land Use in the municipality of Bonito / MS in 1984, 1994, 2004 and 2014.

\begin{tabular}{c|c|c|c|c|c|c|c|c}
\hline \multirow{2}{*}{$\begin{array}{c}\text { Classes de } \\
\text { Uso do Solo }\end{array}$} & \multicolumn{2}{|c|}{1984} & \multicolumn{2}{c|}{$\mathbf{1 9 9 4}$} & \multicolumn{2}{c|}{$\mathbf{2 0 0 4}$} & \multicolumn{2}{c}{2014} \\
$\left(\mathbf{K m}^{2}\right)$ & $\begin{array}{c}\text { Área } \\
(\%)\end{array}$ & $\begin{array}{c}\text { Área } \\
\left(\mathrm{Km}^{2}\right)\end{array}$ & $\begin{array}{c}\text { Área } \\
(\%)\end{array}$ & $\begin{array}{c}\text { Área } \\
\left(\mathbf{K m}^{2}\right)\end{array}$ & $\begin{array}{c}\text { Área } \\
(\%)\end{array}$ & $\begin{array}{c}\text { Área } \\
\left(\mathbf{K m}^{2}\right)\end{array}$ & $\begin{array}{c}\text { Área } \\
(\%)\end{array}$ \\
\hline $\begin{array}{c}\text { Vegetação } \\
\text { Natural } \\
\text { Florestal }\end{array}$ & $\begin{array}{c}2.786,1 \\
5\end{array}$ & 56,50 & 2326,97 & 47,19 & 2163,63 & 43,88 & 1994,93 & 40,45 \\
\hline $\begin{array}{c}\text { Vegetação de } \\
\text { Pastagens }\end{array}$ & 2073,07 & 42,04 & 2497,98 & 50,66 & 2670,96 & 54,17 & 2699,95 & 54,75 \\
\hline Área Urbana & 2,50 & 0,05 & 3,85 & 0,08 & 5,46 & 0,11 & 6,36 & 0,13 \\
\hline $\begin{array}{c}\text { Áreas de } \\
\text { Atrativos } \\
\text { Turísticos }\end{array}$ & 0,00 & 0,00 & 1,52 & 0,03 & 3,32 & 0,07 & 5,78 & 0,12 \\
\hline $\begin{array}{c}\text { Áreas de } \\
\text { Lavouras } \\
\text { Temporárias }\end{array}$ & 4,67 & 0,09 & 10,86 & 0,22 & 35,16 & 0,71 & 162,51 & 3,30 \\
\hline $\begin{array}{c}\text { Corpos } \\
\text { Hídricos }\end{array}$ & 28,77 & 0,60 & 28,54 & 0,58 & 22,54 & 0,46 & 21,76 & 0,44 \\
\hline $\begin{array}{c}\text { Áreas de } \\
\text { Várzea }\end{array}$ & 35,73 & 0,72 & 61,12 & 1,24 & 29,82 & 0,60 & 35,39 & 0,72 \\
\hline Solo Exposto & 0,00 & 0,00 & 0,05 & 0,00 & 0,00 & 0,00 & 4,21 & 0,09 \\
\hline & 4930,89 & 100,00 & 4930,89 & 100,00 & 4930,89 & 100,00 & 4930,89 & 100,00 \\
\hline
\end{tabular}

A maior pressão sobre a vegetação pode ser explicada levando-se em consideração o fato de a atividade pecuária ter se desenvolvido nas últimas décadas. Conforme dados do IBGE (2004), o plantel de cabeças de gado cresceu de 58.523, em 1970, para 236.267 em 1985. Em 1995 havia 303.506, em 2004350.923 e em 2010 foram contabilizadas 401.933 cabeças de gado (SEMAC/MASUL ,2010).

Pode-se verificar, portanto, que houve grande alteração no uso do solo ao correlacionar a evolução das classes mapeadas no período analisado, sobretudo, com destaque para alguns usos como área urbana e áreas de atrativos naturais (Figura 8).

O aumento da área urbana, mesmo que pequeno, justifica-se uma vez que ocorreram grandes loteamentos na área para construção de residenciais, havendo também a abertura de vias terrestres, como avenidas, ruas e logradouros. Assim, os contribuintes principais para essas mudanças foram: a mudança do centro para regiões periféricas da população, a abertura de loteamentos e construção de condomínios. A diminuição dos recursos hídricos pode ser justificada pelas obras de canalização e construção de vias terrestres sobre os principais córregos da hidrografia da bacia. 


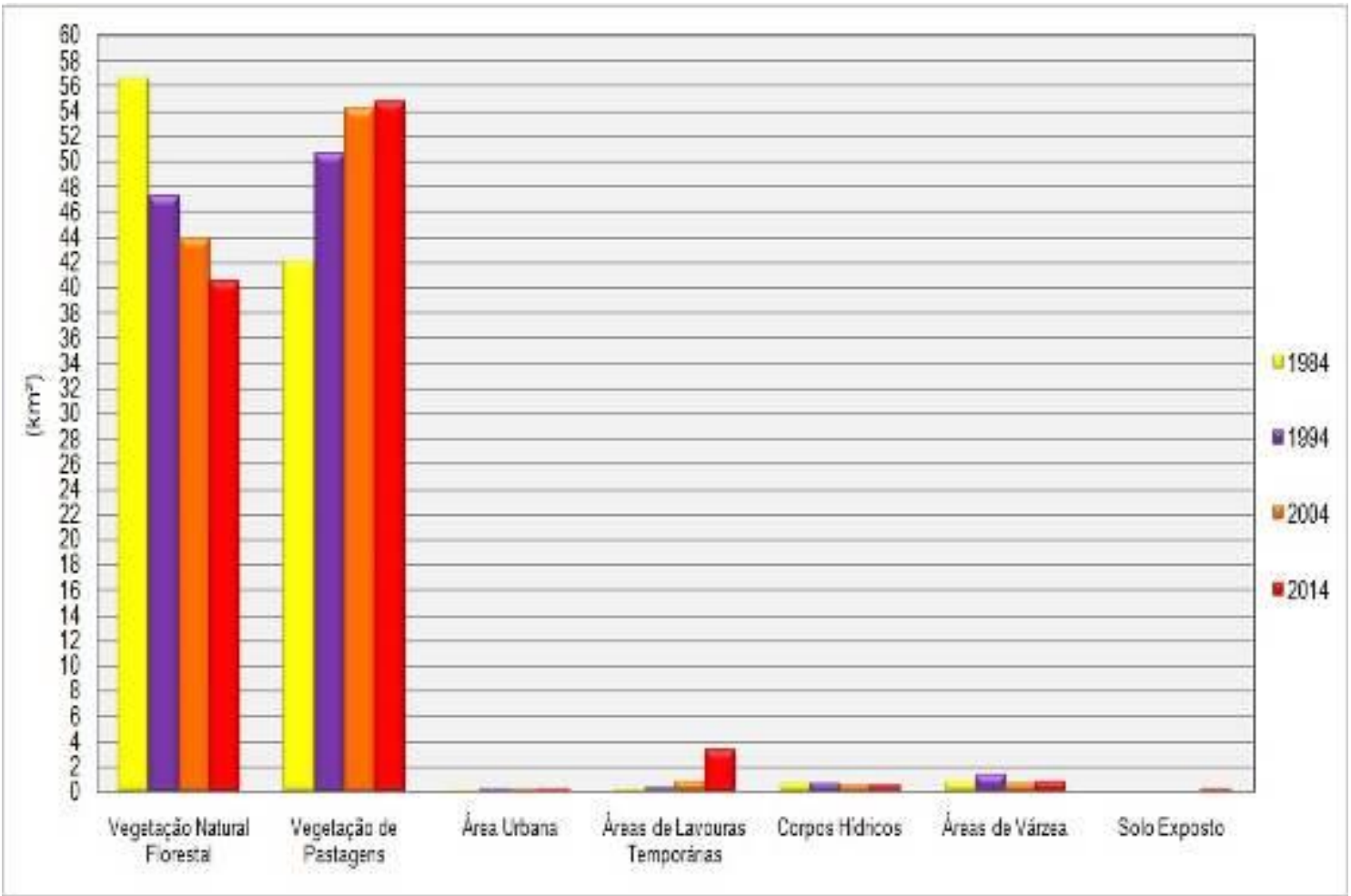

Figura 8: Comparação da área em km², entre 1984 e 2014, das classes temáticas de uso e ocupação do solo.

Figure 8: Comparison of area in $\mathrm{km}^{2}$ between 1984 and 2014, the thematic classes of land use and occupation.

Rezende (2004) procura realçar o caráter de fenômeno social do turismo, envolvendo a prestação de serviços em estreita relação com meio ambiente, que é capaz de produzir impactos com dimensões positivas ou negativas de natureza, tanto físico/ambiental, como econômico e cultural. Destaca, ainda, que tais impactos podem ser minimizados por meio de formas de planejamento que produzam ações voltadas para potencializar as suas dimensões positivas e neutralizar as negativas.

Para Barioulet e Vellas (2000), uns dos fatores que devem ser integrados ao planejamento turístico são os indicadores de impactos sociais, sendo de grande importância selecionar percentuais que possam permitir uma mensuração da contribuição do projeto ao desenvolvimento dos níveis socioeconômicos e educacionais das populações locais também.

Muitas vezes, o processo de planejamento do turismo nas cidades tende a ser algo mais simples ou mesmo inexistente. De acordo com Hardy et al.(2002), é comum que as destinações turísticas sejam criadas por empreendedores, empresas privadas ou mesmo pelo governo nacional, e todo o planejamento parte dessa perspectiva serem elaborados pelos mesmos. Ressalta-se, assim, que o ponto crítico destas formas de planejamento é que todos os afetados pelo plano devem ser efetivamente trazidos para o processo de planejamento, e não incorporados de forma meramente simbólica, pois dessa forma poderão gerar impactos negativos futuramente. 
Portanto, o processo de uso e ocupação do solo no Município de Bonito deve ocorrer de forma planejada, ou seja, seguindo diretrizes urbanísticas e de planejamento ambiental e turístico, que possam garantir o máximo de proximidade da dinâmica natural dos sistemas. Consequentemente, serão evitados problemas relacionados à redução de vegetação e recursos hídricos, elementos essenciais no uso de recursos para a sustentabilidade dos atrativos comercializados em Bonito. Ainda, as imagens ilustram os atuais impactos ambientais e uma previsão de possíveis impactos futuros ambientais negativos.

\section{Considerações Finais}

Podemos considerar que o uso de geotecnologias para a análise das modificações da paisagem, a exemplo do estudo realizado nas imagens de 1984 a 2014, foi de fundamental importância. Cabe destacar a importância de se levantar os impactos e os riscos ambientais de uma determinada região.

Os softwares SPRING e ArcGIS, utilizados para a análise das imagens, mostraram-se como uma importante ferramenta para a avaliação da qualidade ambiental, visto que essa análise conseguiu diferenciar as alterações ocorridas no decorrer destas décadas, ou seja, diagnosticar a realidade referente às classes estudadas, cabendo destaque para os atrativos turísticos.

Pode-se verificar visualmente uma grande alteração no uso do solo, com decréscimo de vegetação em geral, corpo hídrico e aumento do solo exposto e da área urbana. A maior pressão sobre a vegetação pode ser explicada levando-se em consideração o fato de investimentos em outras economias (pecuária e agricultura), além do turismo, o que confirma não ser a atividade principal do Município.

Ainda, o estudo da multitemporalidade contribuiu para o entendimento do processo de construção e análise da região, ao mesmo tempo em que foi aplicado nesta área escolhida. Assim, este estudo poderá ser utilizado como referência para futuros trabalhos que tenham a intenção de comparar a qualidade ambiental no Município, bem como compreender a evolução das atividades implementadas na localidade, visto o objeto turismo não ser a atividade principal, em detrimento de atividades que levam a uma deterioração dos recursos naturais, como a vegetação, os recursos hídricos e o surgimento de solos expostos.

Esta busca do desenvolvimento vem ao encontro dos conceitos da metodologia do GTP, na qual se avalia a integração e a interatividade entre os componentes do sistema de forma a agir de maneira com que os possíveis impactos negativos sejam minimizados e os positivos maximizados, promovendo, assim, o desenvolvimento do sistema turístico como um todo. 


\section{Referências}

BANDUCCI, Á.J.; MORETTI, E.C. Qual Paraíso? : turismo e ambiente em Bonito e no Pantanal. São Paulo: Chronos, 2001. 205p.

BARBOSA, M.A.C.; ZAMBONI, R.A. Formação de um 'Cluster' em torno do Turismo de Natureza Sustentável em Bonito - MS. Texto para discussão n. 772. Brasilia: IPEA, 2000. 47p.

BARIOULET, H.; VELLAS, F. Checklist for Tourist Projects based on Indicators of Sustainable Tourism. Groupe Développement, 2000.21 p.

BERTRAND, G. Paisagem e geografia física global: esboço metodológico. Revista Ra'e Ga, Curitiba, v, 1, n, 8, p. 141-152, 2004.

BERTRAND, G.; BERTRAND, C. Uma geografia transversal e de travessias: o meio ambiente através dos territórios e das temporalidades. Maringá: Massoni, 2007. 185p.

BOGGIANI, P.C.; COIMBRA, A M.; GESICKI, A.L.; SIAL, A.N.; FERREIRA, V.P.; RIBEIRO, F.B.; FLEXOR, J.M. Tufas Calcárias da Serra da Bodoquena. In: SCHOBBENHAUS, C.; CAMPOS, D. A.; QUEIROZ, E. T.; WINGE, M.; BERBERT-BORN, M. (Edit.) Sítios Geológicos e Paleontológicos do Brasil. 1999. Disponível em: $<$ http://sigep.cprm.gov.br/sitio034/sitio034.htm>. Acesso em 05 set. 2015.

CERDOURA, K.B. Compreendendo o surgimento e consolidação do turismo no município de Bonito/MS através da valorização da experiência de seus habitantes. In: ALMEIDA, N.P. Estudos e pesquisas turísticas em Bonito. Campo Grande: Ed. UFMS, 2013. p.177-208.

CPTEC-INPE. Arquivos do Laboratório de Meteorologia e Climatologia, vinculados ao CPTEC-INPE. Campo Grande, 2014.

DECHANDT, S.G. Ecoturismo e seu desenvolvimento: um estudo de caso comparado entre Chapada Diamantina (BA) e Bonito (MS). 2007. 141f. Dissertação (Mestrado em Administração) - Escola de Administração, Universidade Federal da Bahia, Salvador.

DIAS, J. A região cárstica de Bonito, MS: uma proposta de zoneamento geoecológico a partir de unidades da paisagem. Ensaios e ciência, Campo Grande, v. 4, n. 1, p. 09-43. 2000.

DIAS, J. As potencialidades paisagísticas de uma região cárstica: o exemplo de Bonito, MS. 1998. 183p. Dissertação Mestrado (Ciência e Tecnologia) Universidade Estadual Paulista, Presidente Prudente.

FLORENZANO, T. G. Imagens de Satélite para estudos Ambientais. 3 ed. São Paulo: Oficina de Texto, 2011. 114 p; 115 p.

GLCF. Global Land Cover Facility. Earth Sciense. Data Interface. 2014. Disponível em: <http://glcfapp.glcf.umd.edu:8080/esdi/index.jsp>. Acesso em: 15 set. 2014. 
HARDY, A.L.; BEETON, R.J.S.; PEARSON, L. Sustanible tourism: na overwiew of the concept and its position in relation to conceptualization of tourism. Jornal of Sustainable Tourism, v. 10, n. 6, p. 475,496, 2002.

IBGE. Instituto Brasileiro de Geografia e Estatística. Atlas Nacional do Brasil. 3ed. v, único. Rio de Janeiro: IBGE, 2000. 263p.

IBGE. Instituto Brasileiro de Geografia e Estatística. Mapa de Biomas e de Vegetação. Brasília, [Online], 2004. Disponível em: <http://www.ibge.gov.br/home/presidencia/noticias/21052004biomashtml.shtm >.

Acesso em: 09 set. 2014.

IBGE. Instituto Brasileiro de Geografia e Estatística. Manuais técnicos em geociências. 2ed. Rio de Janeiro: IBGE. 2006. n. 7. 91 p.

IBGE. Instituto Brasileiro de Geografia e Estatística. Sinopse de Senso Demográfico 2010 - Mato Grosso do Sul. [Online]. 2010. Disponível em: $<$ http://cidades.ibge.gov.br/painel/populacao.php?lang=\&codmun=500220\&s earch=mato-grosso-do-sul|bonito|infogr\%E1 ficos:-evolu\%E7\%E3opopulacional-e-pir\%E2mide-et\%E1ria>. Acesso em: 05 set. 2015.

LUNAS, J.R.S. Ecoturismo sociedade anônima: sustentabilidade, dilemas e perspectivas do turismo na Serra do Bodoquena - MS. 2006. 309f. Tese Doutorado (Desenvolvimento Sustentável) - Centro de Desenvolvimento Sustentável, Universidade de Brasilia, Brasilia.

MARIANI, M.A.P. Geografia e turismo no paraíso das águas: o caso de Bonito. 2000. 256f. Tese (Doutorado em Geografia) - Departamento de Geografia, Faculdade de Filosofia, Letras e Ciências Humanas, Universidade de São Paulo, São Paulo.

MONTEIRO, C. Geossistemas: a história de uma procura. São Paulo: Contexto, 2001. 132p.

OLIVEIRA, M.T.C. Bonito para quem? Um estudo sobre um destino turístico no Mato Grosso do Sul: situação atual e perspectivas, Bonito, MS, 2010. 192f. Dissertação (Mestrado em Geografia Física) - Departamento de Geografia, Faculdade de filosofia, Letras e Ciências Humanas, Universidade de São Paulo, São Paulo.

PISSINATI, M.C.; ARCHELA, R.S. Geossistema, Território e Paisagem Método de Estudo da Paisagem Rural sob a Ótica Bertrandiana, Geografia, Londrina, v. 18, n. 1, p. 5-31, 2009.

REZENDE, C.F. Ecoturismo como instrumento de desenvolvimento: limites, desafios e potencialidades. 2004. 115p. Dissertação (Mestrado em Administração) -Universidade Federal de Lavras, Lavras.

ROUGERIE, G.; BEROUTCHACHVILI, N. Géosystémes et Paisages: bilan et méthods. Paris: Armand Colins, 1991. 302p.

ROSOLÉM, N.P., ARCHELA, R.S. Geossistema, território e paisagem como Método de Análise geográfica. In: Seminário Latino-Americano de Geografia Física e Seminário Ibero-Americano de Geografia Física, 6, 2010, Coimbra. Anais... Coimbra: Universidade de Coimbra, 2010. 
SEMAC/MASUL. Secretaria de Estado de Meio Ambiente, do Planejamento, da Ciência e Tecnologia e Instituto de Meio Ambiente de Mato Grosso do Sul. Plano estadual de recursos hídricos de Mato Grosso do Sul: resumo executivo. Campo Grande: Editora UEMS, 2010. 114p.

SCHOENMAKERS, R.P.H.M.; WILKINSON, G.G.; SCHOUTEN, T.E. Segmentation of remotely-sensed images: a re-definition for operational applications. In: International Geoscience and Remote Sensing Symposium, 1, 1991, Espoo. Anais... Espoo: IGARSS'91, 3-6, 1991. Digest. Piscataway, IEEE, v.2, p.1087-1090. 1991.

SILVA, M.H.S. PASSOS, M.M.; SAKAMOTO, A.Y. Análise da paisagem do pantanal da Nhecolândia: estudo de caso das lagoas salitradas sob a perspectiva do Modelo GTP (Geossistema, Território e Paisagem). 2012. 100f. Tese Doutorado (Geografia). UNESP: Presidente Prudente.

SOTCHAVA, V.B. O estudo de geossistemas. São Paulo: Ed. Lunar, 1977. $51 \mathrm{p}$.

SOUZA, R.J. O sistema GTP (Geossistema-Território-Paisagem) aplicado ao estudo sobre as dinâmicas socioambientais em Mirante do ParanapanemaSP. 2010. 173f. Dissertação Mestrado (Faculdade de Ciências e Tecnologia) - UNESP-FCT, Presidente Prudente.

SCREMIN-DIAS, E; POTT, V.J; HORA, R.C; SOUZA, P.R. Nos Jardins Suspensos da Bodoquena: Guia para identificação de plantas aquáticas de Bonito e região. Campo Grande: Editora UFMS, 1999. 160p.

TRICART, J. Ecodinâmica. Rio de Janeiro: IBGE, 1977. 231p.

VARGAS, I.A. Ecoturismo e desenvolvimento sustentável em Bonito - MS: elementos de análise para uma educação ambiental. 1998. 180f. Dissertação (Mestrado em Educação) - Universidade Federal de Mato Grosso do Sul, Campo Grande.

VARGAS, I.A. A gênese do turismo em Bonito. In: BANDUCCI JÚNIOR, Á.; MORETTI, E.C. (Orgs.). Qual paraíso? Turismo e ambiente em Bonito e no Pantanal. São Paulo: Chronos/UFMS, p. 127-149, 2001. 
Waldir Leonel: Universidade Estadual de Mato Grosso do Sul, Campo Grande, MS, Brasil.

E-mail: waldir.leonel@gmail.com

Link para o currículo Lattes: http://lattes.cnpq.br/1802908843021664

Mercedes Abid Mercante: Universidade Anhanguera, Campo Grande, MS, Brasil.

E-mail: mercante@terra.com.br

Link para o currículo Lattes: http://lattes.cnpq.br/0923718095850661

José Sabino: Universidade Anhanguera, Campo Grande, MS, Brasil.

E-mail: jose.sabino@uol.com.br

Link para o currículo Lattes: http://lattes.cnpq.br/9198286227068321

Mauro Henrique Soares da Silva: Universidade Federal de Mato Grosso do Sul, Três lagoas, MS, Brasil.

E-mail:mh_soares@yahoo.com.br

Link para o currículo Lattes: http://lattes.cnpq.br/4370286926305960

Milton Augusto Pasquotto Mariano: Universidade Federal de Mato Grosso do Sul, campo Grande, MS, Brasil.

E-mail: miltmari@terra.com.br

Link para o currículo Lattes: http://lattes.cnpq.br/0935409945176042

Data de submissão: 20 de outubro de 2016

Data de recebimento de correções: 05 de maio de 2017

Data do aceite: 05 de maio de 2017

Avaliado anonimamente 